\title{
Analisis Aliran Fluida Refrigeran 134a pada Rotor Radial Berbasis Computational Fluid Dynamics
}

\author{
Ni Putu Rika Puspita Dewi dan Gunawan Nugroho \\ Departemen Teknik Fisika, Fakultas Teknologi Industri, Institut Teknologi Sepuluh Nopember (ITS) \\ e-mail: gunawan@ep.its.ac.id
}

\begin{abstract}
Abstrak-Pemusnahan eksergi pada turbin gas terjadi karena adanya gesekan antara fluida kerja dengan sudu - sudu turbin yang menyebabkan terjadinya pembangkitan entropi pada fluida kerja. Untuk sistem turbin gas dengan fluida kerja yang bertekanan dan temperature rendah, jenis radial turbin tepat diaplikasikan karena mampu beroperasi pada kecepatan tinggi. Dalam penelitian ini dilakukan studi desain geometri rotor turbin tipe radial dengan menggunakan fluida kerja bantu $R$ 134a untuk meningkatkan daya keluaran turbin. Perancangan geometri blade rotor turbin radial menggunakan dua cara yaitu dengan pendekatan numerik dan simulasi CFD. Perancangan dengan pendekatan numerik dan simulasi 3D menggunakan metode yang disarankan oleh Aungier dan Baines. Dari hasil perhitungan Baines, diperoleh daya output rotor turbin hasil perancangan sebesar $10,497 \mathrm{~kW}$. Selain prediksi performansi daya output, dalam perancangan diperoleh penampang meridional dan segitiga kecepatan rotor yang digunakan sebagai input perancangan 3D blade rotor radial. Dengan variasi sudut inlet rotor $0^{\circ}$ dan $7^{\circ}$ diperoleh perbedaan profil aliran. Pada sudut inlet $70^{\circ}$ menghasilkan performa yang lebih baik berdasarkan profil aliran kecepatan dan distribusi tekanan. Karakteristik aliran yang terjadi pada area blade dan sekitarnya yang dibatasi oleh penampang hub dan shroud menyebabkan terjadi aliran turbulen karena nilai densitas dan viskositas fluida kerja yang rendah.
\end{abstract}

Kata Kunci-Airfoil, Blade, Radial, Refrigerant, Twist, Vortex.

\section{PENDAHULUAN}

$\mathrm{S}$ IKLUS Rankine Organik (ORC) merupakan salah satu siklus yang sering digunakan dalam suatu pembangkitan dengan memanfaatkan waste energy dimana fluida yang digunakan berbahan organik [1]. Di Indonesia, penggunaan teknologi ORC masih sangat sedikit karena industri nasional belum ada yang dapat memproduksi komponen sistem ORC, sehingga teknologi ORC dinilai membutuhkan investasi yang tinggi. Untuk saat ini, pemanfaatan siklus rankine dengan fluida kerja organik hanya sebatas untuk alternatif penambahan daya output pembangkitan listrik, dimana uap sebagai sumber utama pembangkit digunakan untuk memanaskan fluida kerja bantu atau yang sering dikenal dengan teknologi siklus biner. Teknologi siklus biner adalah sistem pembangkit listrik dimana fluida bertekanan rendah seperti misal panas bumi, baik berupa uap maupun air panas dimanfaatkan sebagai sumber panas utama untuk memanaskan fluida kedua (fluida kerja) dengan menggunakan alat penukar panas dari fase cair menjadi fase gas. Fase gas dari fluida kerja ini kemudian dialirkan ke dalam turbin yang dikopel dengan generator untuk membangkitkan listrik.

Berdasarkan pada penelitian sebelumnya terkait efisiensi suatu pembangkit listrik bahwa komponen yang berpengaruh besar dalam pemusnahan eksergi terjadi pada turbin [2]. Pemusnahan eksergi pada turbin gas terjadi karena adanya gesekan antara fluida kerja dengan sudu - sudu turbin yang menyebabkan terjadinya pembangkitan entropi pada fluida kerja [3]. Pada tingkatan pertama, entropi pada sistem sangat menguntungkan untuk tingkat selanjutnya, akan tetapi sangat merugikan pada tingkat terakhir karena sudah tidak dimanfaatkan lagi seperti pada proses sebelumnya namun langsung dialirkan ke tingkat selanjutnya pada siklus.

Berdasarkan permasalahan tersebut, maka dibutuhkan beberapa penelitian terkait peningkatan performa turbin agar seluruh energi dapat dikonversi menjadi listrik. Selain peningkatan performa, pengurangan kerugian akibat beberapa faktor unjuk kerja turbin juga perlu dikaji dalam proses ekspansi. Terdapat beberapa jenis turbin gas yang digunakan berdasarkan kebutuhan kondisi operasi. Untuk sistem turbin gas dengan fluida kerja yang bertekanan dan temperature rendah untuk aplikasi siklus rankine organik, jenis radial turbin tepat diaplikasikan karena mampu beroperasi pada kecepatan tinggi.

Perancangan turbin gas yang umum dan banyak dilakukan pada penelitian yang sudah ada berfokus pada perancangan komponen yang berpengaruh besar terhadap performa turbin yaitu pada komponen rotor. Rotor adalah komponen yang berputar pada turbin terdiri dari poros dan sudu - sudu turbin (blade) yang mengubah energi panas fluida menjadi energi kinetik untuk memutar generator. Selain itu telah dilakukan optimisasi pemilihan desain turbin menggunakan fluida kerja R-134a yang dapat menghasilkan peningkatan daya turbin sekitar 3,6\% bila kecepatan dan bentuk blade tertentu dioptimalkan pada rentang yang diuji [4]. Banyak penelitian yang dilakukan pada studi termodinamik dari sistem ORC dan pemilihan fluida kerja dengan fokus utama pada peningkatan efisiensi pembangkit daya. Oleh karena itu, turbin harus didesain agar memenuhi kondisi operasi fluida kerja untuk sistem ORC pada temperatur dan tekanan yang sesuai dengan properti termodinamik fluida kerja. Semakin tinggi nilai efisiensi atau daya yang dapat dibangkitkan oleh turbin, maka semakin baik pula unjuk kerja komponen lainnya dalam satu siklus tersebut.

Berdasarkan permasalahan tersebut maka dalam penelitian ini akan dilakukan studi desain geometri rotor turbin tipe radial dengan menggunakan fluida kerja bantu R-134a untuk meningkatkan daya keluaran turbin. Turbin radial dipilih karena memungkinkan kinerja yang lebih baik untuk skala yang lebih rendah [5]. Tantangan dalam pemodelan numerik turbin radial yang menggunakan fluida kerja bantu masih perlu ditangani untuk memperbaiki desain turbin dan mengoptimalkan ORC dengan lebih baik. Eksperimen terkait 
aliran 3D pada rotor turbin radial sulit untuk dilakukan karena mengingat terbatasnya waktu dan memerlukan biaya yang mahal sehingga simulasi dengan modifikasi blade rotor menjadi salah satu solusi yang akan dilakukan pada tugas akhir ini. Diharapkan dengan perancangan blade rotor dapat dilakukan analisa yang lebih detail terkait pengaruh desain geometri rotor terhadap fenomena aliran 3D fluida kerja dan performa turbin radial.

Tujuan dari penelitian ini adalah untuk menentukan geometri blade rotor radial dengan menggunakn fluida kerja $\mathrm{R}-134 \mathrm{a}$ agar memperoleh daya output maksimal pada range 10 - $20 \mathrm{~kW}$ serta dapat melakukan analisa terhadap karakteristik aliran fluida yang mengalir pada blade rotor radial.

\section{METODOLOGI PENELITIAN}

Berikut merupakan diagram alir dari pelaksanaan penelitian ini:

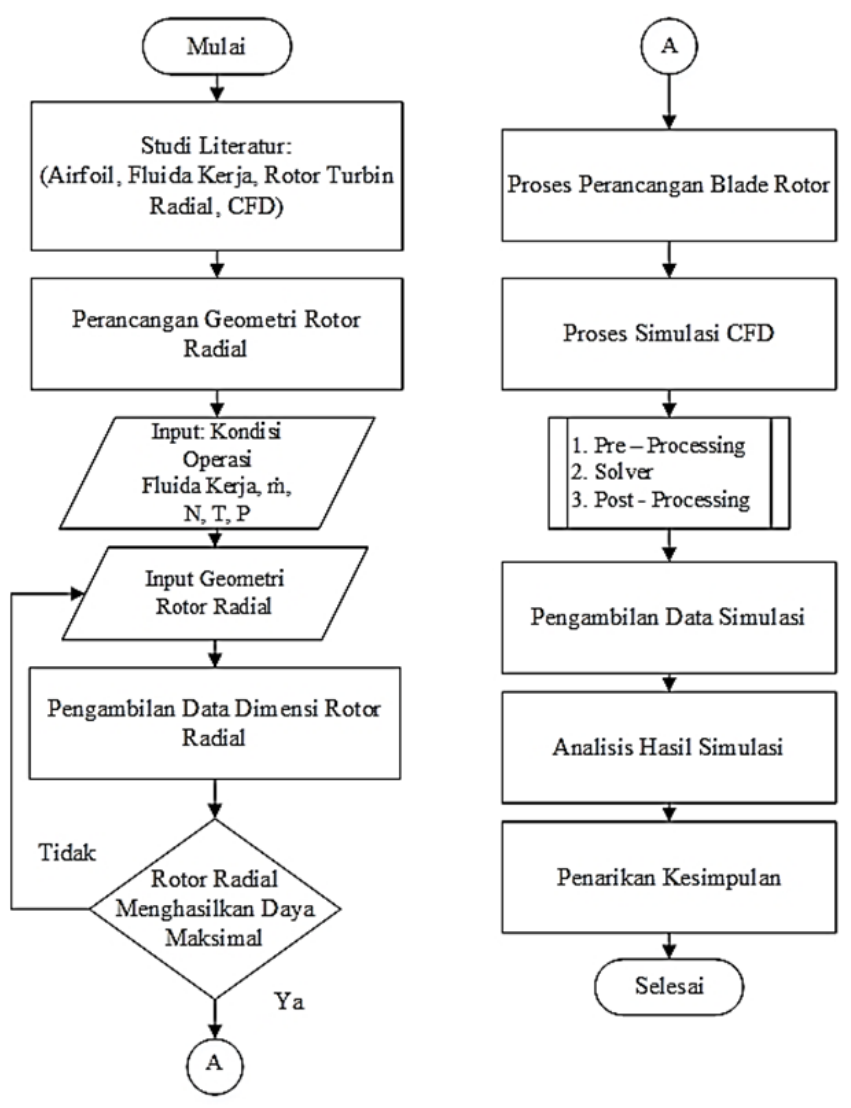

Gambar 1. Diagram alir penelitian.

\section{A. Perancangan Geometri Blade Rotor Turbin Radial}

Perancangan geometri blade rotor turbin radial dilakukan melalui dua tahap yaitu dengan pendekatan numerik dan simulasi CFD. Perancangan dengan pendekatan numerik dan simulasi 3D menggunakan variabel yang disarankan oleh Aungier dan Baines. Pendekatan numerik dilakukan untuk memperoleh perhitungan estimasi geometri blade yang akan diaplikasikan pada rotor turbin radial. Penentuan keadaan awal dipilih oleh penulis sesuai dengan rentang karakteristik termodinamika dari fluida kerja R-134a dan kondisi operasi input sesuai dengan paper eksperimen dengan nilai kecepatan rotasi yang berbeda yaitu 20.000 rpm. Berikut adalah parameter input perancangan awal blade rotor turbin radial dengan fluida kerja R-134a.
Tabel 1.

Parameter Kondisi Input

\begin{tabular}{lc}
\hline \hline \multicolumn{1}{c}{ Parameter Input } & Nilai \\
\hline Laju aliran massa $(\mathrm{m})$ & $0.6 \mathrm{~kg} / \mathrm{s}$ \\
Kecepatan rotasional $(\mathrm{N})$ & $20000 \mathrm{RPM}$ \\
Temperatur total masuk & $373 \mathrm{~K}$ \\
Tekanan total masuk & $3 \mathrm{bar}$ \\
Konstanta panas spesifik $(\mathrm{Cp})$ & $1000,691 \mathrm{~kJ} / \mathrm{kg}$ \\
Konstanta gas spesifik (R) & $81,5 \mathrm{~kJ} / \mathrm{kg}$ \\
Flow inlet angle & $0^{\circ} \mathrm{dan} 70^{\circ}$ \\
Blade speed ratio & 0.6 \\
Target daya output & $10-20 \mathrm{~kW}$ \\
\hline \hline
\end{tabular}

Dari nilai parameter input yang sudah ditentukan tersebut, maka tahap selanjutnya dari perancangan numerik blade rotor turbin radial dilakukan dengan menggunakan software. Vista RTD adalah salah satu program numerik yang digunakan untuk merancang rotor turbin radial dengan mode iterasi satu dimensi (1D). Adapun parameter input Vista RTD pada perancangan numerik rotor turbin radial yaitu berupa kondisi aerodinamika dan karakteristik fluida kerja R-134a berdasarkan data input kondisi awal. Dari hasil perhitungan Baines, diperoleh daya output rotor turbin hasil perancangan sebesar $10,497 \mathrm{~kW}$. Selain prediksi nilai performansi dan output, juga diperoleh gambaran 1D (flow path) arah meridional dari penampang turbin serta segitiga kecepatan seperti pada gambar berikut.

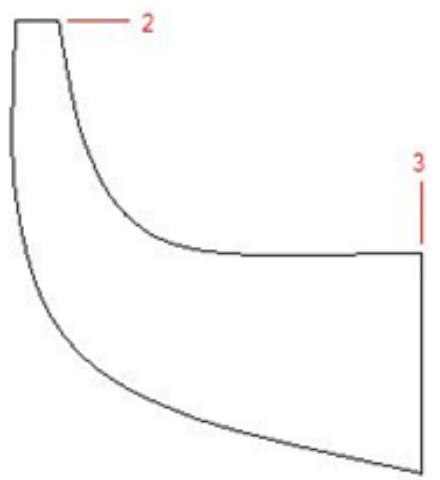

Gambar 2. Dimensi turbin radial penampang merdional.

Tahap selanjutnya dari perancangan geometri adalah tahap perancangan blade rotor dengan software Ansys BladeGen. BladeGen dipilih karena dapat digunakan untuk desain cepat 3D dari komponen mesin berputar seperti rotor turbin. Data hasil perancangan awal digunakan sebagai data input untuk dimensi utama blade rotor turbin pada program Ansys BladeGen. Hal ini dilakukan agar geometri yang dirancang pada tahap simulasi menghasilkan spesifikasi yang rasional. Adapun bagian - bagian rotor yang dapat dikomputasikan berupa geometri blade, hub, shroud, arah input, output, dan rotasi putar. Dalam komputasi perancangan, digunakan 13 blade untuk merepresentasikan bagian rotor turbin secara keseluruhan. Namun output yang dihasilkan pada perancangan dengan BladeGen adalah 1 buah blade (single blade) yang dilengkapi dengan bagian hub dan shroud sebagai tempat dudukan (passage body) blade itu sendiri yang akan dianalisa karakteristik aliran yang terjadi ketika fluida kerja R-134a melalui blade body dari arah inlet sampai dengan outlet rotor. Berikut adalah gambar 3D hasil perancangan rotor turbin radial untuk 13 blade. 


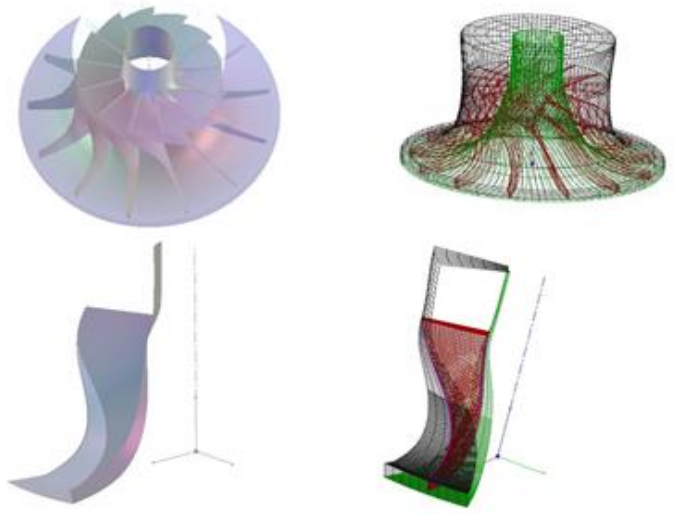

Gambar 3. Geometri blade rotor turbin radial.

Tahap akhir dari perancangan geometri blade rotor turbin adalah mengimport blade rotor ke dalam Desain Modeler. Pada tahap ini seluruh komponen geometri didefinisikan sebagai domain. Berikut adalah hasil perancangan geometri 3D dari rotor turbin radial dengan 1 blade (single blade). Adapun domain yang didefinisikan terdiri dari, bagian blade (blade body), bagian sekitar blade (passage body), aliran masuk fluida (inlet), aliran keluar fluida (outlet), lengkungan permukaan dudukan blade sekaligus poros $(h u b)$, dan lengkungan permukaan yang membentuk batas luar aliran fluida (shroud).

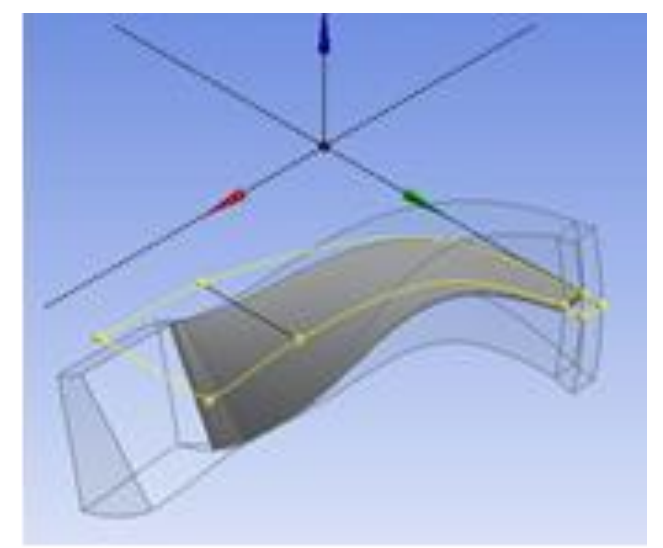

Gambar 4. Single blade rotor turbin radial.

\section{B. Proses Meshing}

Tahap meshing bertujuan untuk menghasilkan mesh sebagai domain komputasi yang umumnya digunakan pada peralatan turbomachinery. Pada tahap ini dilakukan pembuatan grid secara otomatis sehingga dapat menghemat waktu dan biaya. Dalam proses meshing akan dilakukan perhitungan persamaan konversi energi, massa, dan momentum di masing - masing control volume.

Semakin kecil ukuran mesh, maka nilai akurasinya akan semakin baik namun semakin berat juga komputasi yang harus dilakukan oleh software. Ukuran mesh dibedakan untuk tiap bagian rotor seperti pada hub, shroud, dan blade agar hasil simulasi valid tanpa membutuhkan komputasi yang besar. Jenis mesh juga mempengaruhi kualitas mesh yang dihasilkan, dapat dilihat dari beberapa parameter diantaranya elemen quality, skewness, dan orthogonal quality. Semakin tinggi nilai element quality dan orthogonal quality, maka semakin baik nilai meshing. Sedangkan semakin rendah nilai skewness, maka semakin baik hasil meshing. Pada simulasi kali ini penulis menggunkaan mesh jenis tetrahedron.

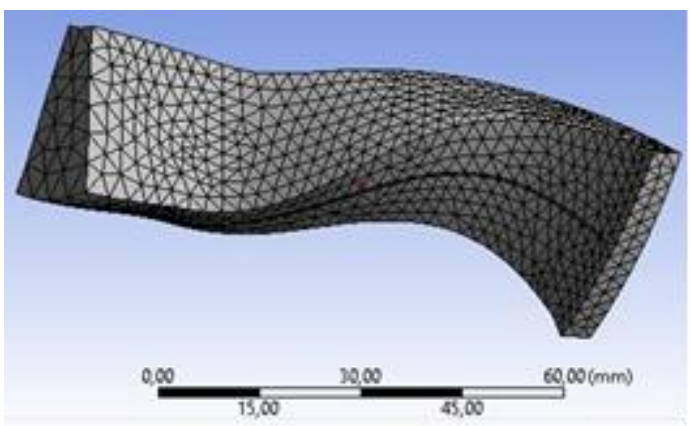

Gambar 5. Meshing passage blade rotor turbin radial.

\section{Proses Simulasi CFD}

Tahap selanjutnya setelah meshing geometri rotor turbin adalah tahap simulasi. Secara umum ada tiga tahap dalam melakukan simulasi CFD yaitu tahap pre processing, solving, dan post processing.

a) Pre processing

Pada tahap ini dilakukan pendefinisian geometri dari domain dan grid generation. Spesifikasi kondisi batas (boundary condition) aliran fluida kerja R-134a disesuaikan dengan properti thermodinamik fluida agar mendapatkan hasil yang valid. Berikut adalah properti termodinamik dari fluida kerja yang digunakan.

Tabel 2.

Properti Termodinamika $\mathrm{R}-134 \mathrm{a}$

\begin{tabular}{ll}
\hline \hline \multicolumn{1}{c}{ Properti Termodinamika } & \multicolumn{1}{c}{$\mathrm{R}-134 \mathrm{a}$} \\
\hline Tipe dan model & Real Gas Redlich - Kwong \\
Molar mass & $102.03 \mathrm{~kg} / \mathrm{kmol}$ \\
Temperature kritis & $374.23 \mathrm{~K}$ \\
Tekanan kritis & $40.59 \mathrm{bar}$ \\
Konstanta panas spesifik & $1000.691 \mathrm{~kJ} / \mathrm{kg}$ \\
Acentric Factor & 0.326 \\
\hline \hline
\end{tabular}

Kondisi batas untuk blade rotor turbin radial pada simulasi ini dapat dilihat pada tabel 3 . berikut.

Tabel 3. Kondisi Batas Simulasi

\begin{tabular}{|c|c|c|c|}
\hline No & Kondisi Batas & Posisi & Kondisi \\
\hline 1 & Inlet & Arah radial & $\begin{array}{l}\text { Mass flow rate } 0,6 \mathrm{~kg} / \mathrm{s} \\
\text { dengan initial pressure } \\
\text { gaugae sebesar } 300.000 \\
\text { Pa dan temperature } 373 \mathrm{~K}\end{array}$ \\
\hline 2 & Outlet & Arah aksial & Outflow \\
\hline 4 & Passage body & $\begin{array}{l}\text { Sekitar blade } \\
\text { (kanan dan kiri) }\end{array}$ & Outflow \\
\hline 5 & Shroud & $\begin{array}{l}\text { Atas domain } \\
\text { blade } \\
\text { (permukaan) }\end{array}$ & Outflow \\
\hline 6 & $\mathrm{Hub}$ & $\begin{array}{l}\text { Bawah domain } \\
\text { blade (dudukan) }\end{array}$ & No slip wall \\
\hline 7 & Single Blade & $\begin{array}{l}\text { Airfoil yang } \\
\text { menempel } \\
\text { dengan hub }\end{array}$ & $\begin{array}{l}\text { Wall (material aluminium) } \\
\text { dengan arah dan } \\
\text { kecepatan rotasi terhadap } \\
\text { sumbu } \mathrm{X}^{+} \text {dan } \mathrm{Y}^{-} \text {sebesar } \\
20000 \mathrm{rpm}\end{array}$ \\
\hline
\end{tabular}

Tipe simulasi dalam keadaan steady dimana parameter aliran tidak berubah terhadap waktu. Model turbulensi yang digunakan dalam simulasi rotor turbin radial adalah model $\mathrm{k}$ - omega $\omega$ jenis Shear Stress Transport (SST) karena dari beberapa penelitian sebelumnya dikatakan bahwa model ini sering digunakan pada aplikasi mesin - mesin turbo yang didesain untuk memberikan akurasi tinggi terhadap letak awal dan jumlah aliran dalam separasi di dalam adverse pressure gradient.

b) Solving

Pada tahap ini dilakukan perhitungan simulasi dari kondisi 
batas yang telah diberikan pada proses sebelumnya yaitu dengan melakukan iterasi sampai hasil yang diperoleh konvergen. Hasil yang konvergen ditandai dengan nilai RMS dibawah $10^{-4}$.

c) Post processing

Setelah proses solving berakhir, maka dilakukan pengambilan data melalui software Ansys CFD Post. Adapun data yang diambil adalah hasil dalam bentuk kontur tekanan dan vector kecepatan pada area sekitar blade rotor.

\section{HASIL DAN PEMBAHASAN}

\section{A. Verifikasi Hasil}

Pada penelitian kali ini, dilakukan verifikasi dan validasi secara kasar dengan membandingkan hasil simulasi yang didapat dengan hasil penelitian sebelumnya yang memiliki kemiripan model. Perancangan geometri dikatakan valid pada penelitian ini apabila blade rotor turbin radial yang dirancang dapat memenuhi target daya output sebesar 10-20 kW sesuai dengan hasil perhitungan pada paper eksperimen yaitu $10 \mathrm{~kW}$ bila diaplikasikan untuk turbin radial pada siklus rankine organik. Pada perancangan desain blade rotor dengan pendekatan numerik segitiga kecepatan rotor turbin diperoleh prediksi daya output sebesar 10,497 $\mathrm{kW}$ untuk kedua variasi desain blade rotor. Sehingga didapatkan nilai error perhitungan dan simulasi sebesar $4.97 \%$.

\section{B. Profil Aliran Pada Variasi Sudut Aliran Masuk}

Analisa dilakukan berdasarkan studi literatur mengenai aliran tiga dimensi pada besaran kecepatan dan tekanan dari profil penampang blade rotor yang dialiri oleh fluida $\mathrm{R}$ 134a. Posisi blade menempel pada $h u b$ dan aliran fluida kerja dibatasi oleh shroud untuk bagian permukaan (selubung) yang merupakan batas aliran luar blade. Sisi sebelah kiri (arah $\mathrm{X}^{-}$dan $\mathrm{Y}^{+}$) merupakan arah putar blade rotor sehingga dapat dikatakan arah putaran blade ke area high periodic dan sisi sebelahnya merupakan area low periodic. Fluida kerja mengalir menuju arah putaran blade rotor. Aliran fluida kerja masuk arah radial mengikuti putaran blade dan keluar arah aksial menuju saluran diffuser bagian atas geometri. Interaksi blade dengan area disekitar putaran blade dapat dianalisa dengan memperhatikan kontur kecepatan dan tekanan yang dihasilkan. Pada simulasi ini, dilakukan dua variasi sudut inlet fluida yaitu $0^{\circ}$ dan $70^{\circ}$ dengan kecepatan rotasi yang sama yaitu 20.000 rpm Berikut akan dibahas secara lebih detail profil aliran fluida kerja R134a yang dihasilkan oleh kedua variasi sudut inlet dan fenomena yang terjadi disekitar area blade rotor.

\section{Profil Kecepatan Aliran Fluida}

Akibat dari rotasi blade rotor kearah high periodic, maka area disekitar blade yang mengalami tumbukkan akan kehilangan tekanan yang tinggi sehingga menyebabkan fluida bergerak cepat. Kecepatan aliran fluida yang masuk rotor pada kedua variasi mengalami peningkatan kecepatan di area sepanjang blade putar (high periodic). Hal ini terjadi karena adanya aliran kecepatan yang bersatu antara aliran fluida masuk rotor dengan kecepatan angular blade rotor. Kecepatan aliran fluida terbesar berada pada area putaran blade rotor yang tinggi.

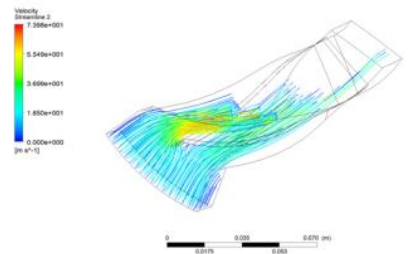

(a)

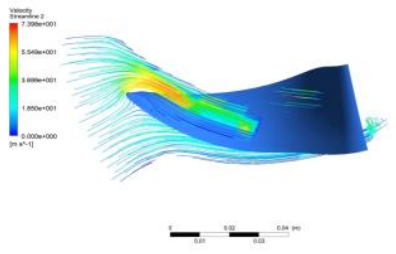

(b)
Gambar 6. Streamline (a) Sudut Inlet $0^{\circ}$ (b) Sudut Inlet $70^{\circ}$.

Pada penampang streamline terlihat aliran fluida bergerak dari arah downstream ke mainstream dimana terjadi perbedaan kecepatan yang cukup signifikan ketika fluida mengenai ujung inlet airfoil pada daerah leading edge. Pola aliran tersebut membentuk titik stagnansi yang menyebabkan terjadi perbedaan kecepatan aliran yang melalui ujung airfoil sampai dengan daerah lengkungan mainstream. Dengan melihat profil streamline, dapat dianalisa aliran fluida yang melewati sisi cekung dan sisi cembung blade rotor yang berbentuk twist tersebut. Pada saat fluida melewati sisi cekung blade, kecepatannya alirannya semakin berkurang, begitu pula ketika fluida kembali melalui permukaan blade yang datar maka kecepatannya akan semakin meningkat. Arah aliran fluida pada kedua variasi hampir serupa ketika melalui area blade dari inlet sampai outlet. Terjadi separasi aliran ketika fluida melalui ujung blade.

Pada variasi sudut inlet $0^{\circ}$ seperti pada Gambar 6a, ketika fluida masuk terseparasi pada dua area blade, dimana pada sisi high periodic, fluida yang dialirkan sejajar outlet nozzle atau tidak membentuk sudut inlet, ketika mengenai permukaan ujung blade aliran dipercepat hingga mencapai kecepatan pada titik maksimum dan diperlambat saat melewati permukaan yang melengkung, dengan kecepatan maksimum pada area inlet rotor sebesar $43 \mathrm{~m} / \mathrm{s}$. Sedangkan pada variasi sudut inlet $70^{\circ}$ kecepatan maksimum area inlet rotor adalah $59 \mathrm{~m} / \mathrm{s}$. Adapun hal yang menyebabkan perbedaan nilai kecepatan inlet pada kedua variasi yaitu ketika fluida melewati permukaan blade dengan arah inlet sejajar dan miring $70^{\circ}$, seperti pada Gambar $6 \mathrm{~b}$ dimana saat aliran fluida masuk sejajar dengan ujung blade yang berbentuk lengkung, maka aliran terseparasi karena momentum aliran yang tidak mampu mengatasi tekanan balik, sehingga pada area tersebut terjadi penurunan kecepatan aliran. Berbeda ketika aliran fluida masuk dibuat miring atau tidak sejajar dengan arah outlet nozzle, maka fluida pertama masuk akan melewati sisi cembung blade, sehingga tidak terjadi pelemahan kecepatan aliran yang signifikan pada area inletnya.

Untuk menganalisa fenomena kecepatan aliran fluida R134a pada single blade rotor, maka kontur aliran kecepatan yang dihasilkan dianalisa berdasarkan interaksi fluida dengan boundary yang terjadi disepanjang area high periodic dan low periodic blade rotor yang berbentuk twist.

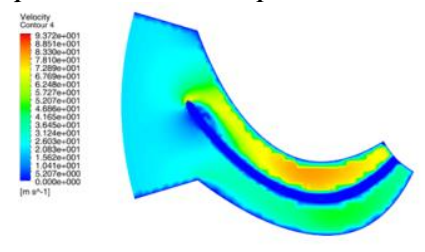

(a)

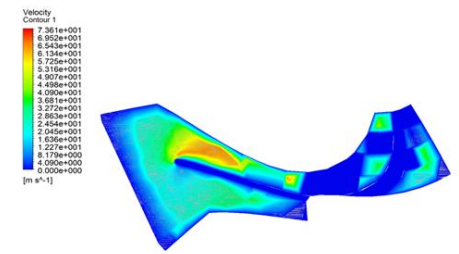

(b)
Gambar 7. Kontur Kecepatan (a) Sudut Inlet $0^{\circ}$ (b) Sudut Inlet $70^{\circ}$. 
Kontur kecepatan tampak seperti pada Gambar 7. Permukaan kontur yang diamati pada kedua variasi adalah pada permukaan shroud, sehingga sisa atas blade merupakan area high periodic (arah putaran blade), sedangkan sisi bawah blade adalah area low periodic. Tampak jelas ketika blade berputar maka area permukaan yang mengalami perubahan kecepatan adalah pada area high periodic. Jika diperhatikan area sepanjang blade, maka tampak bahwa kecepatan aliran fluida yang dekat dengan permukaan blade mengalami penurunan kecepatan dibandingkan dengan area yang jauh dari blade. Fenomena ini dapat dijelaskan dengan konsep aliran yang melewati boundary layer. Pada area yang dekat dengan blade kecepatan aliran lebih kecil akibat pengaruh tegangan geser antara fluida dengan blade body. Selain itu, akibat dari bentuk blade yang twist, maka sisi cembung blade yang semakin jauh dengan permukaan blade mengalami penurunan kecepatan pada area yang lebih luas karena pada sisi low periodic tidak terjadi interaksi antara fluida dengan permukaan padat lainnya.

Pada kedua variasi terdapat perbedaan nilai rata - rata kecepatan inlet, outlet, dan area high periodic. Dengan sudut inlet $0^{\circ}$ diperoleh rata - rata kecepatan aliran fluida di area sepanjang blade sebesar $77.6 \mathrm{~m} / \mathrm{s}$ dan dengan sudut inlet $70^{\circ}$ sebesar $69.52 \mathrm{~m} / \mathrm{s}$. jika dilihat dari nilai rata - rata kecepatan airan fluida maka dengan sudut inlet yang sejajar dengan outlet nozzle akan menghasilkan kecepatan aliran yang lebih tinggi. Perbedaan yang tidak terlalu signifikan mengindikasikan bahwa variasi sudut inlet tidak berpengaruh besar terhadap persebaran kecepatan aliran fluida, karena blade rotor berputar dengan kecepatan yang sama yaitu $20.000 \mathrm{rpm}$. Berdasarkan hasil perhitungan kecepaatn segitiga rotor dengan Vista RTD diperoleh kecepatan blade yaitu $77.6 \mathrm{~m} / \mathrm{s}$. Ketiga nilai kecepatan berada direntang yang tidak terlalu jauh, sehingga dapat dikatakan bahwa kecepatan putar akan blade mempengaruhi kecepatan aliran fluida disepanjang area blade yang berputar.

Untuk menganalisa jenis aliran yang terjadi pada area blade, maka dapat diperhatikan melalui vector kecepatan aliran dari inlet sampai dengan outlet. Karena sudut inlet mempengaruhi pola kontur a liran masuk rotor maka vector kecepatan yang dianalisa pola jenis alirannya adalah dengan sudut inlet $70^{\circ}$ seperti pada Gambar 8 berikut.

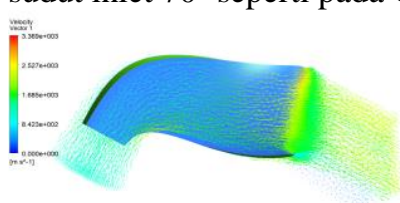

(a)

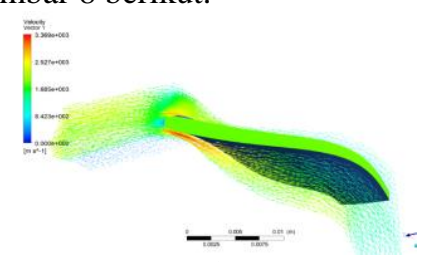

(b)
Gambar 8. Vektor Kecepatan Sudut Inlet $70^{\circ}$ (a) Low Periodic (b) High Periodic.

Pada Gambar 8a merupakan area tampak bagian low periodic (sisi cekung) dimana dari arah atas ke bawah adalah area yang menjauhi $h u b$ (dudukan blade) dan dari kiri ke kanan adalah inlet menuju outlet. Terlihat bahwa kecepatan mengarah dari inlet ke outlet dengan terjadi peningkatan kecepatan dan fluida mengalir mengikuti bentuk blade dengan kecepatan yang berbeda disetiap permukaan yang dilaluinya. Peningkatan kecepatan terjadi pada area yang menjauhi $h u b$, sedangkan pelemahan kecepatan terjadi ketika fluida melewati permukaan cekung blade pada ujung outlet rotor yang menjauhi hub.
Pada Gambar 8b merupakan area tampak bagian high periodic (sisi cembung) dimana dari arah atas ke bawah adalah area yang menjauhi $h u b$ dan dari kanan ke kiri adalah inlet menuju outlet. Sama halnya kecepatan akan menurun ketika mendekati hub dan melewati permukaan blade yang cekung. Berdasarkan vector kecepatan yang terbentuk dan analisa kenaikan kecepatan yang signifikan, maka data dipastikan bahwa jenis aliran turbulen terjadi pada area sepanjang blade rotor radial dengan fluida kerja R-134a.

Berdasarkan analisa profil kecepatan tersebut, selain kedua variasi sudut inlet, maka permukaan blade (sisi cembung dan cekung) juga mempengaruhi profil kecepatan aliran yang terjadi. Interaksi antara fluida dengan dinding $h u b$ juga mempengaruhi kontur kecepatan. Perbedaan kecepatan aliran fluida akan berpengaruh terhadap distribusi tekanan di area sepanjang blade rotor.

2. Distribusi Tekanan Aliran Fluida

Jika melakukan analisa terhadap rotor turbin, maka distribusi tekanan sangat penting dilakukan karena rotor pada turbin bekerja atau berekspansi menyebabkan terjadinya penurunan tekanan yang akan mengindikasikan perubahan entalpi sepanjang blade rotor. Karena simulasi hanya pada satu blade, maka distribusi tekanan yang dianalisa secara detail sepanjang passage body blade, yang terdiri dari area hub, shroud, high periodic, low periodic. Analisa tekanan dikaitkan dengan interkasi fluida dengan permukaan dinding yang ada. Secara hukum Bernoulli, semakin cepat arah putaran suatu benda berputra, maka tekanan yang terjadi pada area tersebut akan menurun, sehingga kecepatan aliran pada area tersebut tinggi. Hukum ini juga berlaku untuk analisa distribusi tekanan yang dihasilkan pada simulasi ini.

Pada Gambar 9 merupakan kontur tekanan pada permukaan shroud untuk kedua variasi sudut inlet. Tampak perbedaan yang cukup signifikan antara distribusi tekanan pada sudut inlet $0^{\circ}$ dan $70^{\circ}$. Sama seperti kontur kecepatan, bagian atas pada gambar merupakan bagian high periodic. Tekanan sepanjang area inlet sampai dengan outlet terjadi penurunan yang cukup signifikan pada kedua variasi. Penurunan tekanan terbesar dihasilkan pasa sudut inlet $70^{\circ}$, ditandai dengan luasnya area berwarna biru muda yang mengindikasikan terjadi penurunan tekanan inlet. Sehingga dapat dikatakan bahwa pada sudut inlet rotor yang besar akan berpengaruh pada pressure drop yang tinggi karena kenaikan kecepatan yang terjadi.

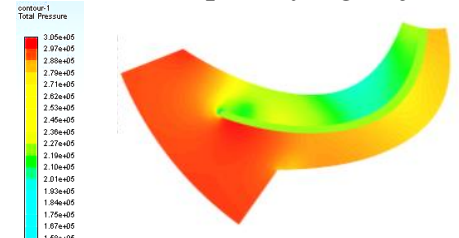

(a)

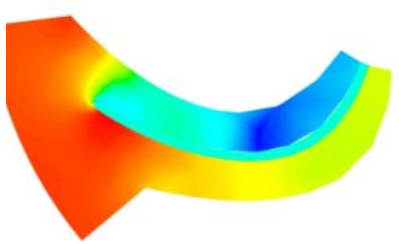

(b)
Gambar 9. Kontur Tekanan (a) Sudut Inlet $0^{\circ}$ (b) Sudut Inlet $70^{\circ}$

Selain kecepatan, hal yang menyebabkan terjadinya penurunan tekanan yaitu permukaan blade yang dilalui oleh fluida. Saat fluida melewati permukaan blade yang cekung maka, tekanan di area tersebut akan lebuh besar dari area yang permukaannya cembung atau datar. Sehingga blade untuk rotor turbin didesain agar fluida yang mengalir menubruk bagian blade yang cembung atau berbalik arah 
dengan sisi cekungnya agar kecepatan aliran fluida meningkat sehingga tekanan yang dihasilkan semakin kecil.

Selanjutnya dianalisa distribusi tekanan pada area permukaan blade yang merupakan batas aliran fluida (shroud) dan pada bagian dinding hub. Karena penurunan tekanan yang tinggi dihasilkan pada variasi sudut inlet $70^{\circ}$, maka yang akan dianalisa secara detail dibeberapa lokasi adalah pada variasi sudut inlet $70^{\circ}$.

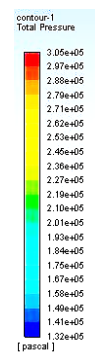

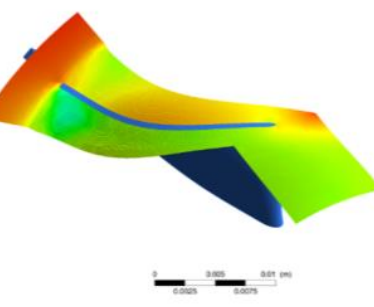

(a)

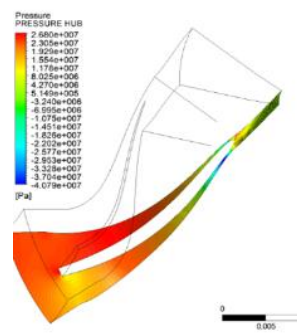

(b)
Gambar 10. Kontur Tekanan Sudut Inlet $70^{\circ}$ (a)Penampang Shroud (b) Penampang $\mathrm{Hub}$.

Pada Gambar 10a merupakan penampang permukaan blade rotor tampak atas atau bagian selubung (shroud), dari kiri ke kanan merupakan arah inlet menuju outlet, bagian bawah blade merupakan bagian high periodic. Tampak bahwa semakin menjauhi hub tekanan yang dihasilkan semakin kecil di area blade yang terkena tumbukkan akibat rotasi blade. Berbeda dengan distribusi tekanan fluida pada area $h u b$, dimana tidak terjadi penurunan tekanan yang signifikan karena dekat dengan dinding. Pressure drop pada area hub terjadi pada permukaan blade yang cembung dan sisi high periodic. Sehingga dapat dikatakan pada area yang dekat dengan dinding, tidak terjadi penurunan tekanan yang signifikan.

Selanjutnya dianalisa distribusi tekanan pada area disekitar blade bagian high periodic dan low periodic dalam bentuk 3D penampang meridional seperti pada Gambar 11 Untuk gambar (a) blade berputar dari arah kiri ke kanan, bagian bawah merupakan yang deat dengan $h u b$, sedangkan gambar (b) blade berputar dari kiri ke kanan dan bagian kiri adalah yang dekat dengan $h u b$. Fluida mengalir dari atas ke bawah mengikuti bentuk penampang meridional blade. Jadi jika dilihat dari bentuk 3D, yang mengalami tumbukkan adalah fluida yang berada pada daerah low periodic. Permukaan blade (sisi cekung dan cembung) dapat dilihat pada Gambar 12 (b).

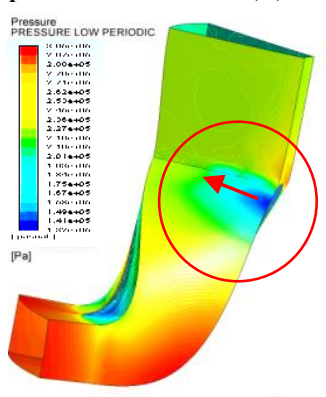

(a)

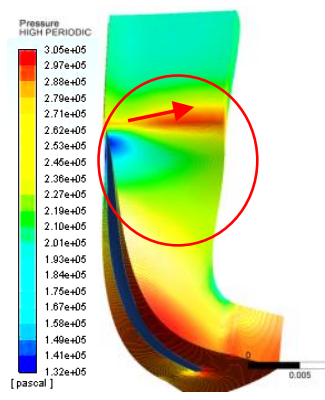

(b)
Gambar 11. Kontur Tekanan Variasi Sudut Inlet $70^{\circ}$ (a) Penampang High Periodic (b) Penampang Low Periodic.

Gambar 11 menunjukkan distribusi tekanan pada daerah disekitar area blade yang memiliki tingkat kecepatan tinggi dan rendah akibat dari arah putaran blade. Terlihat bahwa area kecepatan rotor tinggi, terjadi penurunan tekanan yang cukup signifikan dari inlet menuju outlet baik di area high dan low periodic. Pada gambar (a) fluida mengalami tumbukkan sehingga tekanan berkurang. Pada area yang dilingkari merah, pressure drop tertinggi pada daerah putar blade dan semakin mendekati permukaan yang cekung, terjadi pelemahan kecepatan yang mengakibatkan tekanan di area tersebut lebih tinggi. Berbeda dengan fenomena yang terjadi pada sisi low periodic yang dilingkari merah, tekanan daerah tersebut dipengaruhi oleh bentuk permukaan cekung blade bagian yang dekat outlet, dimana semakin cekung bentuk blade maka tekanan diarea tersebut semakin tinggi, sehingga terjadi pelemahan kecepatan yang cukup signifikan yang berakibat tekanan menjadi tinggi. Pada sisi high periodic tekanan yang dihasilkan lebih rendah karena pengaruh tumbukkan fluida dengan arah putar blade.

Selanjutnya area yang dianalisa adalah bagian inlet dan outlet dari blade rotor, karena penting mengetahui distribusi tekanan masuk dan keluar blade rotor. Seperti yang dijelaskan pada bab sebelumnya, bahwa fluida masuk pada arah radial dan keluar arah aksial. Seperti pada Gambar 12 (a) fluida masuk dari bagian bawah, berputar radial mengikuti arah panah dari kiri ke kanan dan gambar (b) merupakan outlet fluida keluar rotor.
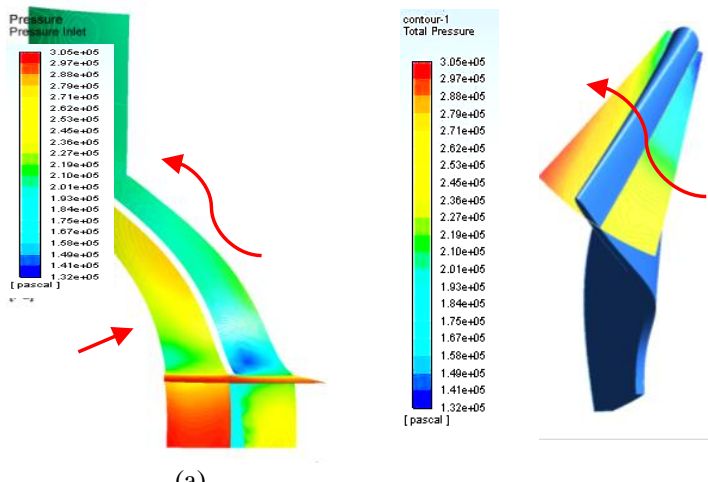

Gambar 12. Kontur Tekanan Variasi Sudut Inlet 70 (a) Area Inlet (b) Area Outlet.

Pada daerah inlet terlihat bahwa tekanan total bernilai konstan sebelum akhirnya mengenai blade rotor. Pada ujung blade inlet mulai terjadi penurunan tekanan yang ditandai dengan perbedaan warna kontur dari merah menjadi kuning. Untuk daerah high periodic, fluida mengalami penurunan tekanan yang cukup signifikan dibandingkan sisi sebelahnya. Akibat dari kecepatan relative rotor, dibeberapa daerah terjadi pressure drop akibat dari adanya gesekan yang besar antara fluida dengan blade rotor. Pada posisi ini dapat dilakukan analisa dampak dari perbedaan daerah high periodic dengan low periodic yang menyebabkan perbedaan tekanan yang sangat jelas pada tekanan yang dimiliki oleh fluida yang berputar pada satu blade. Karena tidak ada interaksi antara blade sebelahnya, tekanan yang dihasilkan oleh fluida merupakan akibat dari interaksi fluida dengan blade.

Pada Gambar 12 menunjukkan bahwa saat aliran fluida memasuki blade rotor dan mengenai penampang leading edge terjadi separasi tekanan fluida. Sedangkan pada outlet rotor terlihat proses ekspansi berada pada tahap akhir dengan penurunan tekanan yang lebih besar pada daerah high periodic. Perputaran rotasi blade ke arah radional menyebabkan secara paksa aliran udara berputar mengikuti arah putaran rotor dengan tujuan agar energi yang dimiliki oleh fluida dapat diekspansi secara keseluruhan sehingga 
menghasilkan daya output yang lebih besar dibandingkan dengan rotor aksial. Berdasarkan hasil simulasi dengan melihat kontur tekanan pada beberapa posisi, dapat dikatakan bahwa dari arah inlet sampai ke outlet proses ekspansi rotor turbin berhasil, karena tekanan yang dihasilkan mengalami penurunan. Semakin kecil tekanan yang ihasilkan maka turbin bekerja secara optimal.

\section{Pembahasan}

Hasil penelitian pada paper eksperimen (Arifin, 2014) mengidentifikasikan bahwa putaran rotor berpengaruh terhadap aliran steady. Dengan mengetahui profil aliran sekitar rotor maka kita dapat menganalisa efek daya dan properti aerodinamikanya. Karena keterbatasan waktu peneliti dalam melakukan simulasi, maka profil aliran yang dianalisa yaitu pada single blade rotor radial turbin dengan menggunakan fluida kerja R-134a. Jika dilihat dari karakteristik termodinamika R-134a, dengan nilai densitas sebesar $511.9 \mathrm{~kg} / \mathrm{m}^{3}$ dan viskositas $1.75 \times 10^{-5}$ maka aliran yang terjadi adalah cenderung turbulen. Hal ini dapat dilihat pada kontur streamline dimana terjadi fluktuasi kecepatan yang tinggi dan tidak teratur. Untuk itu, sangat penting memilih fluida kerja yang memiliki karakteristik termodinamika yang sesuai dengan hasil yang diharapkan pada suatu perancangan dan simulasi aliran.

Pada penelitian ini dilakukan variasi perancangan sudut inlet rotor yaitu $0^{\circ}$ dan $70^{\circ}$, dimana kedua variasi tersebut menghasilkan profil aliran yang berbeda berdasarkan besaran yang dianalisa (kecepatan dan tekanan). Jika dilihat dari profil streamline, perbedaan sudut inlet berpengaruh pada area masuk rotor, dimana jika sudut inlet diperbesar $70^{\circ}$ maka fluida mengalir dengan arah miring (tidak sejajar outlet nozzle), sehingga fluida masuk tidak mengalami separasi yang besar. Jadi, jika blade rotor berputar dengan kecepatatan tinggi (rpm), aliran fluida dapat dijaga/diarahkan agar berputar sejajar atau tetap mengikuti arah putaran rotor. Selain itu, jika sudut inlet tidak diatur akan terjadi fenomena surge dan stonewall. Pemilihan rotor turbin radial berdasarkan sudut inlet bergantung pada kebutuhan, jika ingin merancang turbin radial jenis inflow maka sudut inlet $0^{\circ}$ merupakan pilihan yang tepat karena beroperasi pada rentang kecepatan rotasi yang lebih kecil. Jika dianalisa dari segi perancangan, maka dengan diaturnya sudut inlet rotor atau fungsi nozzle yang dapat mengarahkan dan mengekspansikan energi yang dimiliki fluida menjadi energi kinetic dengan sudut inlet yang optimum, maka performa rotor dapat mencapai daya maksimal melebihi prediksi hasil perhitungan.

Selain profil berupa kontur dan vector kecepatan, profil distribusi tekanan sangat penting dalam analisa rotor turbin. Analisa aliran 3D pada blade rotor radial turbin mengidentifikasi distribusi tekanan di beberapa area atau titik, yang dimana tidak ditemukan pada aliran 2D. Seperti yang ditunjukkan Gambar 13 terlihat jelas area high periodic dan low periodic menghasilkan distribusi tekanan yang sangat berbeda, begitu pula dari area yang dekat dan menjauhi hub dan/dinding blade menuju permukaan shroud. Semakin jauh dari dinding maka tekanan fluida semakin kecil, begitu sebaliknya. Jika dilihat dari arah inlet menuju outlet maka dapat dikatakan dengan penurunan tekanan yang terjadi, rotor radial hasil simulasi dapat dioperasikan sesuai dengan prinsip kerja rotor turbin. Untuk memberikan nilai secara kuantitatif terhadap profil aliran fluida R-134a yang melewati single blade rotor radial turbin, maka berikut adalah data besaran kecepatan, tekanan, dan total entalpi rata - rata yang dihasilkan oleh kedua variasi sudut inlet rotor radial turbin.

Tabel 4.

Data Kuantitatif Hasil Simulasi

\begin{tabular}{lccc}
\hline \hline $\begin{array}{l}\text { Parameter Nilai } \\
\text { Output Rata }-\end{array}$ & Kecepatan & Tekanan $(\mathrm{Pa})$ & $\begin{array}{c}\text { Total Entalpi } \\
(/ \mathrm{kg})\end{array}$ \\
$\begin{array}{l}\text { Rata pada- } \\
\text { Inlet }\end{array}$ & & & \\
Sekitar Blade & $4.903 \times 10^{1}$ & $3 \times 10^{5}$ & $5.673 \times 10^{4}$ \\
Outlet & $4.049 \times 10^{1}$ & $1.957 \times 10^{1}$ & $5.415 \times 10^{4}$ \\
\hline \hline
\end{tabular}

Berdasarkan nilai tersebut, maka pada single blade rotor radial untuk aplikasi pada turbin dapat dikatakan terjadi peningkatan kecepatan fluida disepanjang inlet, area blade, sampai ke outlet. Hal ini diiiringi dengan penurunan nilai tekanan dan total entalpi. Penurunan entalpi mengidentifikasi bahwa pada rotor, energi panas yang dimiliki oleh fluida kerja R-134a diubah menjadi energi kinetik untuk memutar poros.

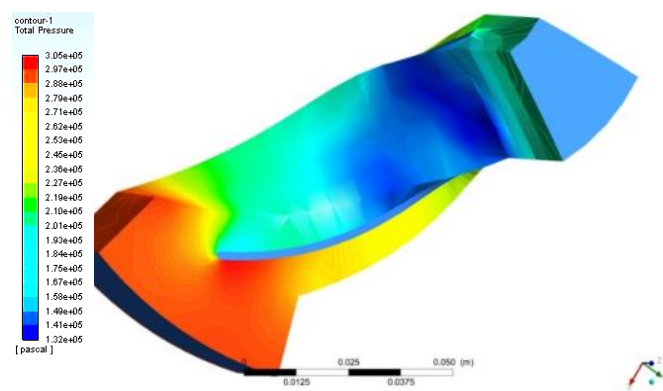

Gambar 13. Kontur Tekanan 3D Passage Body Blade Rotor Sudut Inlet $70^{\circ}$

Berdasarkan hasil perancangan dan simulasi geometri blade rotor radial dapat dikatakan bahwa rotor yang dirancang dengan panjang hub atau chord $61.1418 \mathrm{~mm}$ dapat dioperasikan sesuai dengan kondisi input yang ditentukan untuk satu blade rotor radial. Karakteristik aliran fluida kerja organik yaitu refrigerant 134a yang mengalir pada penampang blade rotor adalah aliran terseparasi yang disebabkan oleh interaksi antara fluida yang mengalir dengan permukaan benda yang cekung. Pada konsep rotor untuk turbin, semakin cekung permukaan suatu benda yang dilalui oleh fluida, maka akan terjadi pelemahan kecepatan aliran pada area tersebut. Namun secara konsep mekanika fluida Hukum Bernoulli, semakin tinggi kecepatan angular, tekanan pada daerah tersebut rendah, sehingga kecepatan aliran fluida yang melalui blade rotor semakin tinggi.

\section{KESIMPULAN}

Berdasarkan hasil simulasi dan analisa yang telah dilakukan, dapat diambil kesimpulan sebagai berikut.

1. Desain geometri untuk blade rotor radial turbin adalah berbentuk twist dengan dimensi airfoil blade yang diperoleh dari perancangan menggunakan software pada Ansys Blade Gen dengan spesifikasi yang disesuaikan dengan daya output yang diharapkan yaitu sebesar $10.497 \mathrm{~kW}$ dengan kecepatan rotasi $20000 \mathrm{rpm}$ untuk aplikasi rotor turbin dengan 13 blade. Adapun dimensi hasil perancangan airfoil memiliki panjang hub dan chord sebesar $61.1418 \mathrm{~mm}$. 
2. Karakteristik aliran fluida R-134a yang melewati single blade rotor radial disebabkan oleh fenomena aliran fluida yang melewati suatu boundary. Permukaan blade dengan sisi cekung dan cembung menyebabkan pola aliran yang berbeda. Semakin mendekati permukaan cekung, kecepatan fluida mengalami penurunan yang berakibat pada peningkatan tekanan, begitu sebaliknya. Semakin tinggi kecepatan putar blade pada suatu area, maka tekanan pada daerah tersebut semakin kecil, sehingga kecepatan aliran fluida yang melewati penampang tersebut semakin tinggi. Hal ini sesuai dengan prinsip Hukum Bernoulli.

\section{LAMPIRAN}

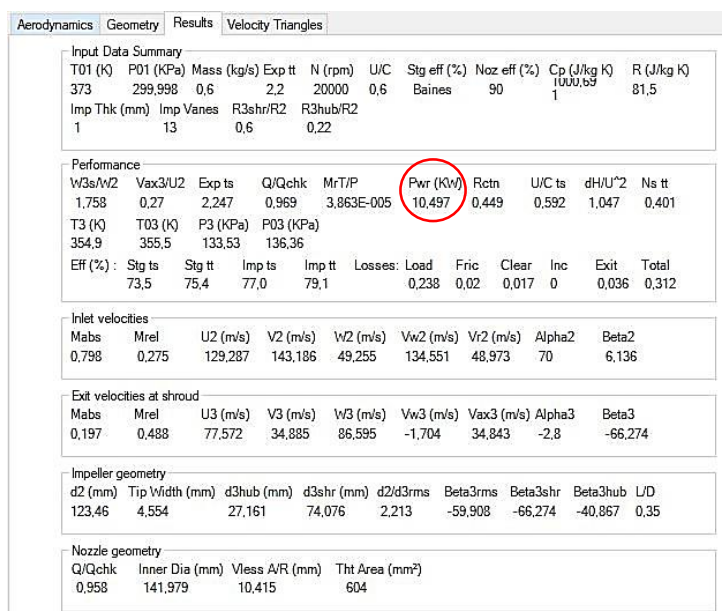

Prediksi Performa Rotor Radial (Ansys Vista RTD).

\section{DAFTAR PUSTAKA}

M. Imran, M. Usman, S. P. Byung, and Y. Yang, "Comparative Assessment of Organic Rankine Cycle Integration for Low Temperature Geothermal Heat Source Applications," Energy, vol. 102, pp. 473-490, 2016

[2] M. Yari, "Exergetic Analysis of Various Types of Geothermal Power Plants," Energy, vol. 35, pp. 112-121, 2010.

[3] D. Balqis, K. Indriawati, and B. L. W., "Optimasi Daya Listrik pada PT Pertamina Geothermal Energy Area Kamojang, Jawa Barat," J. Tek. POMITS, vol. 1, no. 1, pp. 1-6, 2012.

[4] Y. W. Hong and L. P. Kuo, "Optimum Design and Simulation of A Radial-Inflow Turbine for Geothermal Power Generation," Appl. Therm. Eng., vol. 130, pp. 1299-1309, 2017.

[5] H. Amsyari and T. H. Ariwibowo, "Peranc Numerik Turbin Radial untuk Sistem Organic Rankine Cycle," in Seminar Nasional Energi 5 Politeknik Negeri Jember, 2016. 